\title{
TRADUÇÃO DE PRÁTICAS ESTRATÉGICAS: ESTUDO DE CASOS MÚLTIPLOS EM CONSULTORIAS SERGIPANAS
}

\author{
TRANSLATION OF STRATEGIC PRACTICES: MULTIPLE CASE STUDIES IN CONSULTANCIES OF \\ SERGIPE
}

TRADUCCIÓN DE PRÁCTICAS ESTRATÉGICAS: ESTUDIO DE CASO MÚLTIPLE EN CONSULTORÍAS DE SERGIPE

\author{
THIAGO ROOZEVELT DE SOUZA \\ Mestre \\ Universidade Federal de Sergipe - Brasil \\ thiagorzv@yahoo.com.br \\ ORCID: https://orcid.org/0000-0002-8538-7878 \\ LUDMILLA MEYER MONTENEGRO \\ Doutora \\ Universidade Federal de Sergipe - Brasil \\ ludmilla2907@gmail.com \\ ORCID: https://orcid.org/0000-0003-2346-7589
}

Submetido em: 03/05/2018

Aprovador em: 28/02/2019

Doi: alcance.v26n1(Jan/Abr).p030-044

\begin{abstract}
RESUMO
A tradução de práticas estratégicas da organização pelos praticantes ocorre a partir do momento em que uma ideia de origem externa é interpretada pelos agentes de uma organização e aplicada em um contexto diferente daquele que foi originado. Entendendo ser possível a convergência de uma abordagem microrrelacional da estratégia (Estratégia como Prática Social) com uma abordagem estratégica macrocontextual (Teoria Institucional), este trabalho tem como objetivo compreender como ocorre a tradução de práticas estratégicas pelos praticantes a partir do estudo de caso em três consultorias do estado de Sergipe. A pesquisa é de natureza qualitativa, do tipo descritiva. Os dados foram coletados por entrevistas semiestruturadas realizadas com informantes-chave das organizações pesquisadas, além da análise documental e observação não participante. Em seguida, esses dados foram triangulados para conferir mais robustez à análise, realizada por meio de uma análise de conteúdo. Os resultados apontam que, em duas empresas pesquisadas, a tradução ocorre por transmissão e também por corrente, devido ao uso de tecnologias extraídas diretamente do fornecedor, mas também passam pelo crivo de outras empresas; enquanto na terceira empresa, a tradução é mediada por outros atores e organizações a partir da atuação de uma pessoa específica.
\end{abstract}

Palavras-chave: Tradução de Práticas Estratégicas. Estratégia como Prática Social. Teoria Institucional.

\section{ABSTRACT}

The translation of strategic organizational practices by practitioners occurs from the moment an idea originating externally is interpreted by the agents of an organization and applied in a different context than the original one. Understanding that the convergence of a microrrelacional approach to strategy (Strategy-as-Practice) with a macrocontextual strategic approach (Institutional Theory) is possible, this study seeks to understand how the translation of certain strategic practices by practitioners occurs, through a case study of three consultancies at the 
state of Sergipe. This is a qualitative study, of the descriptive type. Data were collected through semi-structured interviews with key informants of the studied organizations, supplemented by document analysis and nonparticipant observation. These data were then cross-referenced in order to improve the data analysis, which was performed using content analysis. The results reveal that in two of the companies studied, the translation occurs by transmission and also by stream, due to the use of technology extracted directly from the supplier, but it also passes under the scrutiny of other companies. In the third company, translation is mediated by other actors and organizations, based on the performance of a specific person.

Keywords: Translation of Strategic Practices. Strategy as Practice. Institutional Theory.

\section{RESUMEN}

La traducción de prácticas estratégicas por los practicantes ocurre desde el momento en que una idea de origen externo se interpreta por agentes de una organización y se aplica en un contexto diferente de lo que se originó. Entendiendo que es posible la convergencia de un enfoque microrelacional a la estrategia (Estrategia como práctica social) con un enfoque estratégico macrocontextual (Teoría Institucional), este estudio tiene como objetivo entender cómo se hace la traducción de prácticas estratégicas por los practicantes, desde el estudio de caso en tres consultorías del estado de Sergipe. Esta investigación es cualitativa, descriptiva. Los datos fueron recolectados por medio de entrevistas semi-estructuradas con informantes claves de las organizaciones encuestadas, además de documentar el análisis y la observación no participante. Estos datos fueron triangulados con el fin de proporcionar más solidez al análisis por medio de un análisis de contenido. Los resultados apuntan que, en dos empresas encuestadas, la traducción ocurre por transmisión y por corriente, debido al uso de tecnologías extraídas directamente del proveedor, pero también pasan por el tamiz de otras empresas, mientras que, en la tercera empresa, la traducción es mediada por otros actores y organizaciones, por la actuación de una persona específica.

Palabras clave: Traducción de Prácticas Estratégicas. Estrategia como práctica. Teoría Institucional.

\section{INTRODUÇÃO}

O campo de estudos da estratégia organizacional consolidou diversas abordagens que consideram diferentes perspectivas a respeito da relação entre a organização e o seu ambiente externo e a influência desta na formulação e na execução da estratégia organizacional. Uma teoria amplamente adotada para entender essa relação é a Teoria Institucional, que parte das premissas de que os componentes de um sistema devem estar interligados entre si para sua sobrevivência (assim, a mudança em um componente requer mudanças adaptativas de outros componentes) e que as estruturas existentes contribuem para o funcionamento de um sistema social (o que leva à busca da identificação das consequências funcionais e disfuncionais dos diferentes arranjos estruturais). A consideração dos efeitos das forças ambientais sobre a organização, a percepção do agente decisório como um indivíduo de racionalidade limitada, os fatores simbólicos inerentes às estruturas organizacionais e outras explicações contribuíram para a evolução da teoria (Tolbert \& Zucker, 2012).

Tal visão, entretanto, ao permanecer num nível macro das empresas e dos mercados, acaba desconsiderando a ação humana na análise. Clegg, Carter e Kornberger (2004) apontam que essa limitação traz a necessidade de se modificar a forma como a estratégia organizacional é considerada. Assim, novas diretrizes da pesquisa estratégica, ao focar no papel do estrategista, procuram humanizar a pesquisa (Jarzabkowski, Balogun \& Seidl, 2007), dando primazia às abordagens microrrelacionais, localmente definidas e historicamente contextualizadas, experimentadas e vividas por indivíduos no interior das organizações, tendo como objetivo entender a real participação das pessoas na formulação e na execução da estratégia.

O artigo de Whittington (1996), Strategy as Practice, apresentou a perspectiva da Estratégia como Prática Social, uma abordagem que tem como um de seus focos compreender a efetividade da atuação de um estrategista dentro da organização. Segundo Rese et al. (2017), o estrategista é capaz de traduzir grandes narrativas que orientem o desenvolvimento das atividades empresariais cotidianas, em um nível micro de realização da estratégia.

Nem sempre é fácil alinhar duas perspectivas aparentemente excludentes como a Estratégia como Prática Social e a Teoria Institucional, porém Golsorkhi et al. (2010) estabelecem que a abordagem prática é 
compatível com abordagens macro, de forma a analisar como atividades microrrelacionadas se ligam com práticas institucionalizadas, de forma a compreender aquilo que é realmente executado nas organizações e como essas atividades reproduzem ou mudam entendimentos e práticas em vigor. Isso foi previsto por Dimaggio e Powell (2005), que apontaram a necessidade de uma Teoria da Prática para desenvolver uma visão balanceada entre atores e instituições, explicando o relacionamento entre a ação humana e as estruturas e culturas em que os atores se inserem, já que nenhuma abordagem isolada possui a capacidade de explicar todas as questões envolvendo a estratégia, o "fazer estratégia" (strategizing) e as relações entre micro e macrocontextos.

Dessa forma é possível estabelecer um território comum para as pesquisas que unam as duas teorias e preencham a lacuna de pesquisas com tais perspectivas. Boxenbaum e Pedersen (2009) reabilitam o papel dos atores sociais ao considerarem sua imersão em um campo organizacional, com organizações que percebem e interpretam pressões institucionais e como isso afeta a prática cotidiana. Junto a essa perspectiva estão o conceito de tradução e a noção de que as ideias mudam quando transitam de um contexto para outro, diferentemente da difusão pelo isomorfismo institucional.

Considerando que ambas as teorias apresentam uma perspectiva complementar das práticas sociais e podem ser utilizadas em conjunto, o presente estudo busca compreender como ocorre a tradução de práticas estratégicas pelos praticantes a partir de um estudo de casos múltiplos, realizado em três consultorias do estado de Sergipe, que procurou identificar as práticas estratégicas adotadas pelos praticantes das organizações pesquisadas, identificar os processos de isomorfismo institucional e analisar o processo de tradução das práticas estratégicas por meio do uso de ferramentas estratégicas pelos praticantes.

Na seção 2, são apresentados os pressupostos teóricos relacionados à Estratégia como Prática Social, à Teoria Institucional e à articulação entre as duas teorias. Na seção 3, são descritos os procedimentos metodológicos e na seção 4 são descritos os casos e a análise comparativa entre eles com base na literatura utilizada. Por fim, são detalhadas as considerações finais do estudo e as sugestões para futuras pesquisas.

\section{REFERENCIAL TEÓRICO}

\subsection{Estratégia como Prática Social}

A Estratégia como Prática Social tem origens advindas de uma abordagem processual da estratégia. Segundo Johnson, Melin e Whittington (2003), a tendência anterior dos estudos sobre estratégia era o foco nos resultados, e não nas atividades que conduziam a esses resultados; posteriormente, a preocupação passou a ser com processos e práticas detalhados que formam o cotidiano da vida organizacional, relacionados com os resultados estratégicos.

A Estratégia como Prática Social, em linhas gerais, compromete-se em compreender como os gerentes executam a estratégia. Unindo-se à visão processual da estratégia, a Estratégia como Prática Social busca entender a prática dos estrategistas, levando em conta aquilo eles falam e fazem (Jarzabkowski, 2004; Whittington, 1996). Esta perspectiva implica uma nova direção do pensamento e das pesquisas sobre estratégia.

A pesquisa convencional em estratégia, segundo Jarzabkowski e Spee (2008), gerou uma insatisfação nos pesquisadores ao reduzir os atores e a ação humana a um conjunto de dados demográficos. Este fato trouxe a necessidade de a pesquisa em estratégia estudar os elementos que representam comportamentos rotineiros, que sustentam as atividades cotidianas nas organizações. Para Rese et al. (2017), nesse momento a estratégia passa a ser compreendida como uma prática social.

Para uma teoria baseada na prática, Jarzabkowski, Balogun e Seidl (2007) destacam três termos essenciais para 0 entendimento da Estratégia como Prática Social: (1) Práxis: São as rotinas dos atores organizacionais e a relação entre essas ações e o contexto institucional, social e organizacional em que elas ocorrem; (2) Práticas: São as tradições, as rotinas, os procedimentos e as normas que constituem o trabalho da estratégia, por meio dos hábitos sociais caracterizados na forma de fazer determinada atividade cultural; e (3) Praticantes: São os atores da ação, indivíduos que fazem e refazem um sistema de práticas estratégicas compartilhadas. A interseção entre práxis, práticas e praticantes gera o strategizing, ou seja, o processo constante de fazer estratégia em uma organização. Conforme Balogun, Huff e Johnson (2003), o strategizing é o estudo das práticas realizadas pelos seus praticantes no local onde ela ocorre dentro de um dado contexto inserido.

O fortalecimento das pesquisas na temática da Estratégia como Prática Social deve considerar alguns aspectos. Em geral há a tentação de limitar a pesquisa aos métodos etnográficos ou de observação. Porém,

Revista Alcance - Eletrônica - vol. 26 - n. 1 - Jan./Abr. 2019 
Balogun, Huff e Johnson (2003) defendem que, em se tratando de grandes corporações diversificadas, com unidades e áreas dispersas mundialmente, são necessários métodos mais flexíveis e de maior amplitude de investigação. Já Jarzabkowski e Whittington (2008) apontam que a análise dos casos deve ocorrer com base em uma teoria sólida não apenas na Economia, mas em campos diversos (Etnometodologia, Antropologia e Teoria Institucional, por exemplo), de forma que diferentes metodologias aprofundem o entendimento em como os praticantes realmente atuam.

Embora a Estratégia como Prática Social tenha se institucionalizado rapidamente e de forma eficaz (Carter, Clegg \& Kornberger, 2008), ela não está isenta de críticas. Os autores apontam que muitas das contribuições trazidas pelos autores da Estratégia como Prática Social já haviam sido trazidas por autores clássicos, o que se correlaciona com o fato da estratégia como prática buscar, da mesma forma que as perspectivas anteriores, auxiliar os gestores a gerirem melhor as organizações em que atuam.

Johnson, Melin e Whittington (2003) denominam a Estratégia como Prática Social de Visão Baseada em Atividades. É considerada uma atividade, formada por microatividades (ações humanas individuais) e macroatividades (práticas socialmente definidas), que se utilizam do conhecimento formal e tácito para sua execução. Na visão de Rese et al. (2017), a Estratégia como Prática Social não somente direciona esforços para o nível micro de análise, por atribuir papel relevante aos praticantes, mas também busca uma compreensão ao nível macro, na medida em que as práticas sociais estão relacionadas a regras e recursos que estruturam a ação social dos sujeitos. Assim, perspectivas como a Teoria Institucional, junto à Estratégia como Prática Social, são capazes de consolidar a virada em direção à prática, ao assumir que os atores não podem ser deslocados do contexto social.

\section{$2.2 \quad$ Teoria Institucional}

A Teoria Institucional, na concepção de Machado-da-Silva e Gonçalves (2012), é uma convergência de diversas perspectivas teóricas que incorporam a ideia da existência de padrões, contratos e regras que dirigem as relações entre indivíduos, grupos e organizações. Também é dito por Coraiola e Machado-da-Silva (2008) que, para esta teoria, a realidade se apresenta como uma construção social, realizada por diversos sujeitos a partir das suas ações.

Em uma organização, a institucionalização é uma alternativa para mudanças necessárias, pois como afirmam Tolbert e Zucker (2012), as transformações ocorrem por meio da eficiência por adequações de conformidade adotadas na gestão organizacional. A institucionalização é percebida como um conjunto de processos sequenciais que sugerem variabilidade nos níveis de institucionalização, em que alguns padrões de comportamento social estão mais sujeitos do que outros à avaliação crítica, à modificação ou à eliminação.

Para Dimaggio e Powell (2005), as pressões isomórficas são os mecanismos que impulsionam a organização em direção à mudança, e tais pressões se relacionam com os diversos atores presentes no ambiente interno e externo. Como um mecanismo de mudança institucional, pode ser visto como um processo que restringe uma dada unidade da população a se assemelhar a outras unidades também inseridas no mesmo conjunto de pressões ambientais, e de forma semelhante, as organizações que sofrem essas pressões passam a se parecer a outras organizações do mesmo ambiente.

Dessa forma, Dimaggio e Powell (2005) estabelecem que a capacidade de descrever os campos organizacionais em termos de estrutura, processo e comportamentos é obtida por meio da análise das pressões isomórficas que geram mudanças, como leis, regras, culturas, normas éticas e outros. Esse isomorfismo tem duas formas: competitivo e institucional. O primeiro trata apenas da competição no mercado, enquanto o isomorfismo institucional leva as organizações a competirem por poder político, adequação social e econômica e legitimação institucional. Sua presença é marcante num ambiente ordenado por regulações legais. Dentro das mudanças institucionais, são propostos três mecanismos que conduzem a essas mudanças: 0 isomorfismo coercitivo, 0 isomorfismo mimético e o isomorfismo normativo. Tais mecanismos são causados por diferentes tipos de pressões e podem estar inter-relacionados, derivando de condições diferentes e podendo levar a resultados distintos em cada organização.

O isomorfismo coercitivo, segundo Dimaggio e Powell (2005), é resultante de pressões formais e informais exercidas por outras organizações e correspondentes às expectativas criadas pela sociedade. Pressões essas que variam entre a coerção, a persuasão ou um convite para agir em conluio. Organizações maiores podem 
estabelecer as regras ou as estruturas já legitimadas, impondo-as nas organizações em posição de dependência e que estão em busca de legitimidade.

Já o isomorfismo mimético é descrito por Dimaggio e Powell (2005) como a ação das organizações em tomar outras como modelo como decorrência da incerteza, que leva a uma economia para tais organizações, quando têm à sua frente um problema com causas ambíguas e soluções pouco nítidas. Tolbert e Zucker (2012) apontam que as soluções já implantadas por outras organizações é uma solução barata, já testada e que pode ser usada mais rapidamente.

A profissionalização é a principal fonte geradora de isomorfismo normativo, conforme Dimaggio e Powell (2005), que a descrevem como a luta coletiva dos membros de uma profissão para definir métodos e condições do seu trabalho, de forma a controlar a produção e estabelecer uma base conceitual para a legitimação que traz autonomia à profissão.

A institucionalização, segundo Tolbert e Zucker (2012), é vista como o processo por meio do qual os componentes da estrutura formal tornam-se amplamente aceitos, legitimando as organizações. Para Powell e Colyvas (2008), é a respeito da necessidade de se construir uma abordagem de múltiplos níveis, compreendendo diferentes níveis de institucionalização, devido ao fato dos atores não estarem engajados somente em criar instituições, mas também em mantê-las e destituí-las. Desprezar esse aspecto de relações sociais contínuas em que os atores estão inseridos é apresentar "atores heroicos" que não contribuem com a literatura. Isso conduz à etapa seguinte, que representa a tentativa de integrar as perspectivas distintas da Estratégia como Prática Social e da Teoria Institucional.

\subsection{Diálogo entre a Estratégia como Prática Social e a Teoria Institucional}

Integrar as perspectivas da Teoria Institucional e da Estratégia como Prática Social não é simples devido a uma lógica dualista existente nos estudos sobre Estratégia. Segundo Suddaby, Seidl e Lê (2013), as diferenças entre as perspectivas da Teoria Institucional e Estratégia como Prática Social residem, principalmente, no fato de que a primeira é mais antiga e voltada a uma perspectiva macro (com foco no campo organizacional), enquanto a segunda é mais recente e com uma orientação "micro", interessada em compreender como as interações entre indivíduos influenciam as decisões e os comportamentos competitivos da empresa. Já as semelhanças residem no fato de que ambas as teorias questionam a perspectiva da racionalidade econômica dos agentes e compartilham de um pragmatismo teórico e empírico comum, buscando descrever aquilo que as organizações realmente fazem.

A complementaridade entre as duas teorias, ainda segundo Suddaby, Seidl e Lê (2013), reside no fato de que, nos aspectos em que uma teoria mais peca, a outra a complementa e vice-versa. A Teoria Institucional auxilia no entendimento da ação dos mecanismos institucionais; enquanto a Estratégia como Prática Social foca na cognição, no comportamento ou emoção dos atores, apreendidos no cotidiano organizacional. A tendência atual é que as teorias caminhem na direção de complementar suas fraquezas, cujas instituições são resultados contingentes de interações em curso e interpretações intersubjetivas dos indivíduos e grupos sociais por meio dos quais eles são constituídos, pois os atores têm um grau limitado de reflexividade sobre a sua relação com as estruturas sociais que eles construíram e certa capacidade de mudá-los.

Powell e Colyvas (2008) destacam a relevância do indivíduo/ator na abordagem institucional, a partir do reexame da relação entre agência e instituições, da importância de observar comportamentos, motivações e relacionamentos dos indivíduos, que pelas práticas diárias executam processos de criação, manutenção, ruptura e mudança institucional. Essa análise considera a linguagem e os arquivos como essenciais para essa compreensão. Ao mesmo tempo, na perspectiva da Estratégia como Prática Social, Whittington (2006) evidencia que as práticas estratégicas de uma organização se originam tanto de um contexto organizacional quanto de um contexto institucional (externo à organização).

Porém, Zilber (2006) aponta um problema quanto ao uso do termo difusão pelo isomorfismo institucional, ao estabelecer que a maioria dos estudos sobre institucionalização foca em aspectos estruturais ou práticos, negligenciando a dinâmica das ideias e dos aspectos simbólicos. Esses estudos, em geral, partem de um modelo baseado na difusão das ideias, em que as práticas são adotadas de forma plena, demonstrando uma noção estática do processo. 
Considerando que a Teoria Institucional examina não só o ambiente material, mas também aspectos simbólicos e culturais, Zilber (2006) define que desenvolvimentos teóricos levaram a uma mudança de um modelo baseado na difusão para um modelo baseado na tradução, melhorando a compreensão dos processos institucionais e a sua dinâmica simbólica. A metáfora difusão vem da física e traz a ideia da transmissão de uma dada entidade de uma área para outra; já a metáfora tradução vem da linguística e conota uma interação que envolve negociação entre as partes e uma reformulação antes de ser transmitido (institucionalizado).

Como forma de superar os conflitos e as contradições e fortemente baseados numa teoria da prática, Suddaby, Seidl e Lê (2013) estabelecem que o trabalho institucional (institutional work) é um meio de levar a Teoria Institucional às raízes fenomenológicas e concentrar a atenção nos processos em si, e não sobre as estruturas sociais que são o resultado de processos de institucionalização. Este movimento inspira-se a partir de teoria da prática, enxergando os atores como negociadores dentro do ambiente institucional, por meio de uma ação inteligente situada, e as instituições são vistas como estruturas contingentes ou processos emergentes.

Outra contribuição útil para a junção das duas teorias são os estudos de pesquisadores da Escandinávia, que em sua maioria veio a ser conhecida como Institucionalismo Escandinavo, descritos por Boxenbaum e Pedersen (2009) como uma abordagem dos estudos organizacionais baseada em fatores contextuais que levam a destacar fatores de variação e distinção, em vez de isomorfismo e padronização, em que variações significativas entre as organizações podem ser versões ligeiramente diferente de organizações com formas semelhantes, destacando o papel de atores e da ação na análise institucional.

Para Sahlin e Wedlin (2008), o Institucionalismo Escandinavo incorpora à Teoria Institucional uma tradição de pesquisa baseada em metodologias qualitativas, que estudam a tomada de decisão individual, mudanças e reformas organizacionais, destacando aspectos da circulação de ideias, como e por que elas se generalizam, como são traduzidas, como fluem e as consequências organizacionais. Tais ideias podem ser ferramentas de gestão, modelos organizacionais e certificações diversas. A partir do momento que modelos, atores ou práticas se tornam amplamente conhecidos, eles moldam os desejos e ideais dos outros e impulsionam a imitação. A circulação de ideias faz parte dos processos de imitação e tradução ao envolver a dinâmica de formação de identidade, de forma que algumas organizações tendem a ser mais propensas a imitar e mais receptivas a novas ideias do que outras.

A imitação, conforme Sahlin e Wedlin (2008), é um processo com participação ativa dos imitadores, que adaptam determinada ideia à sua dinâmica organizacional. Ela pode ocorrer por meio de um modelo de núcleo ou conjunto específico de ideias, captado por atores em várias configurações e incorporado às práticas locais, de forma a levar a uma homogeneização das práticas. A imitação também pode ocorrer por cadeia, quando não é o modelo original, e sim suas imitações que são alvo da imitação. Por fim, ela também pode ser mediada a partir da atuação de determinados atores que agem como transportadores ou mediadores entre a organização imitada e os imitadores. Esses três tipos são ideais e dificilmente vistos em sua forma pura.

\section{PROCEDIMENTOS METODOLÓGICOS}

Nesta seção são descritos os procedimentos metodológicos utilizados no estudo. As questões de pesquisa, para Collis e Hussey (2005), refletem a natureza do problema de pesquisa. Com base no problema definido para esta investigação, Como ocorre a tradução de práticas estratégicas pelos praticantes nas empresas $A, B$ e $C$ ?, foram definidas as seguintes questões de pesquisa: (1) Quais são as práticas estratégicas adotadas pelos estrategistas?; (2) Quais os processos isomórficos presentes nas empresas analisadas?; e (3) Nessas organizações, como ocorre o processo de tradução das práticas estratégicas, por meio do uso de ferramentas estratégicas pelos praticantes?

Baseado na terminologia adotada por Saunders, Lewis e Thornhill (2007), o presente estudo foi pautado numa perspectiva interpretativista, pelo método indutivo, o que se adequa tanto à Teoria Institucional, pela possibilidade de analisar as práticas institucionais por meio da análise dos campos organizacionais e de elementos culturais, históricos e discursivos (CORAIOLA; MACHADO-DA-SILVA, 2008); quanto à Estratégia como Prática Social, que vê a estratégia como realização de pessoas nas organizações por meio da inter-relação entre prática, práxis e praticantes (Rese et al., 2017).

A estratégia de pesquisa adotada é o estudo de caso. Segundo Yin (2001), o estudo de caso é um tipo de investigação que preserva as características holísticas e significativas dos eventos da vida real, contribuindo para a compreensão de fenômenos individuais, organizacionais, sociais e políticos. Das possíveis aplicações do 
estudo de caso, duas são adequadas à presente pesquisa: explicar os vínculos causais em interpretações complexas da vida real e também descrever uma intervenção e o contexto na vida real em que ocorre.

A unidade de análise para esta pesquisa são empresas de consultoria organizacional da região metropolitana de Aracaju/SE, escolhidas por disponibilidade, cujos tomadores de decisão, gestores, assistentes e funcionários são os informantes-chave da pesquisa. Os dados foram coletados por meio de entrevistas e observação não participante. Como o objeto de estudo são empresas pequenas, que não ultrapassam 18 funcionários, foram coletadas 5 entrevistas em cada companhia, totalizando 15 entrevistas, as quais permitem traçar um panorama consistente para responder as questões de pesquisa propostas. As entrevistas foram realizadas e gravadas nos meses de setembro e outubro de 2015 e posteriormente transcritas.

Para a análise dos dados, Yin (2001) define essa etapa como o exame, a categorização e a classificação em tabelas, ou a recombinação das evidências com base em proposições iniciais de um estudo. Para o autor, 0 pesquisador deve partir de uma estratégia analítica geral, definindo as prioridades de análise e o porquê, a partir de um estilo rigoroso de raciocinar, da apresentação de evidências suficientes e da análise cuidadosa de interpretações alternativas, para "tratar as evidências de uma maneira justa, produzir conclusões analíticas irrefutáveis e eliminar interpretações alternativas" (Yin, 2001, p. 133). A Figura 1 detalha as categorias analíticas e os elementos de análise que formaram a base para este estudo, com base nas questões de pesquisa e nas categorias preestabelecidas a partir da revisão teórica realizada:

\begin{tabular}{|c|c|c|}
\hline QUESTÕES DE PESQUISA & $\begin{array}{l}\text { CATEGORIAS } \\
\text { ANALITICAS }\end{array}$ & ELEMENTOS DE ANÁLISE \\
\hline \multirow{3}{*}{$\begin{array}{l}\text { Quais são as práticas } \\
\text { estratégicas adotadas pelos } \\
\text { estrategistas? }\end{array}$} & Práticas administrativas & $\begin{array}{l}\text { - Rotinas de trabalho. } \\
\text { - Planejamento estratégico. } \\
\text { - Sistemas de controle. } \\
\text { - Treinamento. }\end{array}$ \\
\hline & Práticas episódicas & $\begin{array}{l}\text { - Eventos. } \\
\text { - Reuniões formais. } \\
\text { - Reuniões informais. }\end{array}$ \\
\hline & Práticas discursivas & $\begin{array}{l}\text { - Comunicação interna. } \\
\text { - Comunicação com o público externo. }\end{array}$ \\
\hline \multirow{3}{*}{$\begin{array}{l}\text { Quais são os processos } \\
\text { isomórficos presentes nas } \\
\text { empresas analisadas? }\end{array}$} & Isomorfismo normativo & $\begin{array}{l}\text { - Dados sobre o ramo de atuação. } \\
\text { - Dados dos estrategistas (área de atuação, escolaridade, } \\
\text { experiência profissional). } \\
\text { - Critérios para seleção de pessoal. }\end{array}$ \\
\hline & Isomorfismo mimético & $\begin{array}{l}\text { - Definição das metas. } \\
\text { - Tecnologias adotadas. } \\
\text { - Mudanças recentes na sua área de atuação. } \\
\text { - Influência da concorrência e de outras organizações em } \\
\text { sua organização. }\end{array}$ \\
\hline & Isomorfismo coercitivo & $\begin{array}{l}\text { - Como ocorrem as mudanças na organização e por que } \\
\text { elas ocorrem. } \\
\text { - Participação em órgãos como conselhos, sindicatos, } \\
\text { associações, etc. }\end{array}$ \\
\hline \multirow{3}{*}{$\begin{array}{l}\text { Nessas organizações, como } \\
\text { ocorre o processo de tradução } \\
\text { das práticas estratégicas, por } \\
\text { meio do uso de ferramentas } \\
\text { estratégicas pelos praticantes? }\end{array}$} & Por transmissão & \multirow{3}{*}{$\begin{array}{l}\text { - Fontes das ideias. } \\
\text { - Os atores que captam as ideias. } \\
\text { - Quais atores (se houver) editam e transportam as ideias. } \\
\text { - Em quais práticas as ideias são implantadas. }\end{array}$} \\
\hline & Por corrente & \\
\hline & $\begin{array}{l}\text { Mediado por outros } \\
\text { atores e organizações }\end{array}$ & \\
\hline
\end{tabular}

Figura 1. Categorias analíticas e elementos de análise

Fonte: Elaborada pelos autores, com base em Dimaggio e Powell (2005), Jarzabkowski (2004), Sahlin e Wedlin (2008) e Whittington (2006).

Nesta pesquisa, os casos foram analisados por meio da análise de conteúdo. Na definição de Berg (2001), a análise de conteúdo abrange qualquer técnica para efetuar inferências por meio da sistemática e objetiva identificação especial das características de mensagens obtidas. Os critérios utilizados devem contabilizar cada variação do conteúdo da mensagem e devem ser aplicados de forma consistente para que outros pesquisadores ou leitores, procurando as mesmas mensagens, obtenham resultados iguais ou comparáveis, validando os

Revista Alcance - Eletrônica - vol. 26 - n. 1 - Jan./Abr. 2019 
eventuais achados da pesquisa. Os casos selecionados foram descritos individualmente e, em seguida, comparados uns com os outros, para atingir os objetivos estabelecidos por Yin (2001): firmar uma análise baseada em evidências relevantes, abranger interpretações concorrentes, focar nos aspectos mais significativos e usar 0 conhecimento prévio, alinhado ao referencial teórico da pesquisa.

\section{DESCRIÇÃO E ANÁLISE DOS CASOS}

Nesta seção, são apresentados os resultados da pesquisa de campo, a partir de uma descrição individual dos três casos e da análise comparativa. A Figura 2 apresenta os entrevistados por sua função e códigos, que serão utilizados durante a análise dos dados.

\begin{tabular}{|l|l|c|}
\hline CASOS & \multicolumn{1}{|c|}{ ENTREVISTAS } & CÓDIGO \\
\hline \multirow{4}{*}{ Caso A } & Diretor Geral (sócio fundador) & $\mathrm{A} 1$ \\
\cline { 2 - 3 } & Gerente Financeiro & $\mathrm{A} 2$ \\
\cline { 2 - 3 } & Estagiária em Recursos Humanos & $\mathrm{A} 3$ \\
\cline { 2 - 3 } & Estagiária em Planejamento e Controle de Produção & $\mathrm{A} 4$ \\
\cline { 2 - 3 } & Representante Comercial & $\mathrm{A} 5$ \\
\hline \multirow{4}{*}{ Caso B } & Diretor de Gestão de Talentos & $\mathrm{B} 1$ \\
\cline { 2 - 3 } & Diretora-Presidente & $\mathrm{B} 2$ \\
\cline { 2 - 3 } & Assessora de Gestão de Talentos & $\mathrm{B} 3$ \\
\cline { 2 - 3 } & Assessora de Projetos & $\mathrm{B} 4$ \\
\cline { 2 - 3 } & Staff de Jornalismo & $\mathrm{B} 5$ \\
\hline \multirow{4}{*}{ Caso C } & Diretor-Presidente & $\mathrm{C} 1$ \\
\cline { 2 - 3 } & Diretor de Comunicação e Marketing & $\mathrm{C} 2$ \\
\cline { 2 - 3 } & Diretor de Tecnologia & $\mathrm{C} 3$ \\
\cline { 2 - 3 } & Gerente de projetos de desenvolvimento de softwares & $\mathrm{C} 4$ \\
\cline { 2 - 3 } & Desenvolvedor front-end & $\mathrm{C} 5$ \\
\hline
\end{tabular}

Figura 2. Fontes de evidência (entrevistas)

Fonte: Elaborada pelos autores.

\subsection{Análise do caso $\mathrm{A}$}

O caso A é uma empresa de consultoria e treinamento criada em 2003 e sediada na cidade de Aracaju/SE. Em sua missão, a empresa é descrita como "uma empresa de educação executiva, consultoria e serviços na área de engenharia de produção que tem na inovação e no desenvolvimento de tecnologia a sua inspiração e o seu compromisso em desenvolvê-los e de transformar suas ações em momentos de realização e prazer para seus clientes". Possui como visão "ser reconhecida pela capacidade de entender e desenvolver produtos que atendam às necessidades dos clientes bem como pela associação dos seus serviços a momentos de realização e prazer". Dentro deste escopo, a empresa B atua na parte de estratégia, serviços e implantação de sistemas de gestão (como as Normas ISO).

$\mathrm{O}$ entrevistado $\mathrm{A} 1$ tem 50 anos e é o sócio fundador do caso A. Ele se identificou como Diretor-Geral. Ele é engenheiro mecânico e possui mestrado em Administração, com experiência em engenharia e docência. Já o entrevistado A2 tem 58 anos e é o gerente financeiro, tendo realizado um curso técnico em contabilidade. A entrevistada A3 tem 23 anos e se identificou como estagiária da área de Recursos Humanos (ainda em formação) e é graduanda em Psicologia. A entrevistada A4 também tem 23 anos, é graduanda em Engenharia de Produção e atua como estagiária em Planejamento e Controle de Produção. Por fim, a entrevistada A5 tem 27 anos, é publicitária e atua como representante comercial. Como foi observado pela entrevistada A4:

Há uma diferença de idades entre as pessoas aqui dentro, ou são jovens ou já são mais maduros, e isso dificulta a integração da gente.

Em relação ao primeiro objetivo específico estabelecido nesse trabalho (identificar as práticas estratégicas adotadas pelos praticantes das organizações estudadas), foram descritas as práticas adotadas por cada empresa, conforme relatado pelos entrevistados. Na empresa A, as práticas estratégicas estão relacionadas 
à oferta de cursos diversos, adaptados conforme a demanda. Conforme o entrevistado $\mathrm{A} 1$ apontou, a economia do estado de Sergipe é movimentada principalmente pelo setor do petróleo, e a grande maioria das empresas está relacionada direta ou indiretamente com esse setor econômico. Também afirmou o seguinte:

\begin{abstract}
Nós adotamos um modelo de planejamento estratégico que nós também vendemos ao mercado, como um produto. Esse modelo consiste inicialmente na análise do segmento de mercado com base nas cinco forças de Porter, além de uma previsão de macroambiente, para saber as perspectivas de negócio com base em dados econômicos.
\end{abstract}

Além da mudança no conteúdo e na oferta dos cursos, a empresa do caso A também buscou diversificar a sua atuação, criando dois novos negócios atrelados à atividade de consultoria, que são: uma cafeteria, anexa ao local onde funciona a consultoria, que tanto atende o público externo quanto o público dos cursos; e uma fábrica de uniformes corporativos, que ainda não está em funcionamento, devido à crise econômica - um fator citado durante a entrevista que também influencia na formação das práticas estratégicas mais adequadas ao momento da empresa.

No entanto, os cursos ofertados ainda são o principal campo de atuação da empresa, que buscou atuar em duas ênfases: 0 oferecimento de cursos novos e atualizados com a realidade do mercado sergipano e no fortalecimento da área de vendas, de forma a superar uma deficiência nessa área, apontada pelo próprio diretor geral da empresa.

O segundo objetivo específico deste trabalho foi identificar os processos de isomorfismo institucional. Para a empresa do caso $\mathrm{A}, \mathrm{O}$ isomorfismo normativo se expressa a partir da seleção de pessoal voltada às necessidades da empresa para um determinado momento - como a empresa passou a ter um maior foco na área de vendas, a seleção de uma publicitária com experiência anterior nessa área foi essencial para que a empresa pudesse definir os métodos de trabalho para estabelecer uma base de legitimidade, adequado à uma estrutura enxuta.

Já em relação ao isomorfismo mimético, é expresso pelo conhecimento do mercado de das mudanças que nele ocorrem, de forma a transformar essas informações em novos produtos ou na adequação dos existentes. Isso fica claro na postura adotada pela empresa como reação a uma crise econômica, como sugere a resposta da entrevistada A5:

Algumas medidas estão sendo tomadas, como por exemplo alugar as salas daqui para outros cursos, para não ficarem ociosas. A gente faz revisões nos preços, tentamos baratear o curso o quanto for possível, de forma a passar por essa crise.

Por fim, o isomorfismo coercitivo não foi muito expresso por meio da participação em associações, no entanto a situação de crise econômica do Brasil foi o maior fator de coerção apontado, levando a mudanças na forma de ação da empresa do caso $A$.

O terceiro objetivo foi analisar o processo de tradução das práticas estratégicas, por meio do uso de ferramentas estratégicas pelos praticantes, entendendo-se a tradução como a interação entre duas partes a qual envolve a negociação e a reformulação de uma determinada prática antes de ser institucionalizada. Em relação ao caso $\mathrm{A}$, os cursos novos ofertados ao mercado são consequência da análise das necessidades das empresas para um contexto de retração econômica, usando as normas da ABNT e também com base na interpretação pessoal do sócio fundador da empresa (entrevistado A1), que estabelece:

As influências costumam ser mais externas, muitas das coisas implantadas surgem por viagens ou cursos, que geram insights.

Pode-se então saber como ocorre a tradução de práticas estratégicas pelos praticantes nas três empresas pesquisadas. A terminologia adotada por Sahlin e Wedlin (2008) considera que os tipos apontados (por transmissão, por corrente e mediado por outros atores e organizações) são ideais e dificilmente vistos em sua forma pura. Para a empresa do caso A, a forma mais adequada é a de tradução mediada por atores ou

Revista Alcance - Eletrônica - vol. 26 - n. 1 - Jan./Abr. 2019 
organizações. Aqui, o entrevistado A1, sócio fundador da empresa, exerce a função de trazer novas ideias e diretrizes para a empresa a partir do entendimento de que uma empresa depende da inovação para continuar existindo. Os novos cursos são ofertados a partir de alguma observação a respeito do mercado feito pelo sócio fundador, adaptando à realidade do mercado local.

\title{
4.2 Análise do caso B
}

O segundo caso é de uma empresa júnior, sediada na Universidade Federal de Sergipe, no campus de São Cristóvão, criada em 1993, vinculada ao curso de Administração da UFS. Sua missão é: "Promover o desenvolvimento sustentável através da prestação de serviços de consultoria, visando à satisfação dos nossos clientes, a qualificação prática dos acadêmicos e bem-estar da sociedade". A autodescrição contida no perfil oficial da rede social facebook, informa que:

\begin{abstract}
(A empresa) é uma empresa de consultoria vinculada à UFS (Universidade Federal de Sergipe) que tem como principal objetivo proporcionar o desenvolvimento de seus clientes através de soluções personalizadas de alta qualidade e baixo custo, representando assim a melhor opção em consultoria para micro e pequenos empresários. Aplicamos os conceitos aprendidos na universidade, a (empresa) contribui para o crescimento dos futuros profissionais que ingressam nela, as nossas consultorias são realizadas mediante a orientação e treinamento de profissionais e professores da UFS com experiência e especialização nas áreas atuantes.
\end{abstract}

A empresa possui onze funcionários e sua estrutura organizacional possui quatro diretorias subordinadas à presidência: Diretoria Administrativa-Financeira, Diretoria de Marketing, Diretoria de Projetos e Diretoria de Gestão de Talentos (o nome dado para os Recursos Humanos). Além das diretorias, alguns funcionários prestam serviço na forma de staff, sem vinculação a alguma diretoria. Anualmente ocorre ao menos um processo seletivo para a admissão de novos membros, de forma a suprir a necessidade de pessoal. Por estatuto, todo diretor e também o presidente só pode ficar por uma gestão na atividade, com duração de um ano. A posse da nova diretoria ocorre todo mês de dezembro.

O entrevistado B1 se apresentou como Diretor de Gestão de Talentos, tem 20 anos e está no $5^{\circ}$ período do curso de Administração, não possuindo experiência profissional anterior (uma quase constante, em se tratando de funcionários que atuam em empresas juniores). Com o "entrevistado" B2, na verdade, tratou-se de uma entrevista coletiva, composta pela Diretora-Presidente (20 anos, $3^{\circ}$ período de Administração), Diretor interino de Marketing (24 anos, $7^{\circ}$ período de Administração), Diretor Administrativo-Financeiro ( 23 anos, $1^{\circ}$ período de Administração) e o Diretor de Projetos (20 anos, $5^{\circ}$ período de Administração). Já a entrevistada B3 se apresenta como Assessora de Gestão de Talentos, possui 19 anos e está no $3^{\circ}$ período de Administração. A entrevistada B4 se apresenta como assessora de projetos, tem 19 anos e está no $3^{\circ}$ período de Administração. Por fim, a entrevistada B5 se apresenta como staff de jornalismo, tem 20 anos e está no $3^{\circ}$ período de Jornalismo.

Quanto ao objetivo de identificar as práticas estratégicas adotadas pelos praticantes das organizações estudadas, identificou-se que, na empresa do caso B, as práticas estratégicas estão relacionadas ao tipo peculiar de empresa que são, uma empresa júnior (mesma situação do caso $\mathrm{C}$ ). Nesse aspecto, a principal prática estratégica da empresa B, mais importante do que o oferecimento de serviços a outras empresas, é 0 aprendizado dos membros, como na perspectiva do strategizing. Segundo Whittington (1996), há um interesse em desenvolver o desempenho individual, o que é possível por meio do uso de tecnologias e sistemas adotados pelas grandes empresas - Podio, Runrun.it, modelo Canvas etc.

Para que isso aconteça, é importante que cada membro esteja informado das tendências da área de negócios, tendo contato com empresas juniores, outras empresas, professores, profissionais e associações do ramo. A tradução das práticas estratégicas, dessa maneira, é algo bastante individualizado, em que a participação de cada membro é maior na adoção e na tradução de uma dada prática estratégica. Em relação à rotina de trabalho, a entrevistada B4 informa o seguinte: 
Oscila bastante, nós passamos por muitas fases, dependendo de se a gente está atendendo algum cliente no momento, acontece também de nos ocuparmos mais com trabalhos internos e outras fases com vários projetos simultâneos.

Já em relação ao objetivo de identificar os processos de isomorfismo institucional para a empresa do caso $\mathrm{B}, \mathrm{o}$ isomorfismo normativo, que se manifesta em aspectos da profissionalização e educação formal, é percebido numa empresa júnior a partir dos cursos e dos treinamentos ministrados aos membros, visto ser esse o objetivo de uma empresa júnior - preparar o estudante universitário, ao concluir o curso, para o mercado profissional.

0 isomorfismo mimético é evidenciado no momento em que a empresa pesquisa sobre as tecnologias gerenciais adotadas pelas grandes corporações e buscam adotá-las; enquanto que, em relação ao isomorfismo coercitivo, a participação em outros órgãos por parte da empresa júnior pesquisada é mais voltada às associações de profissionais da área de administração, em detrimento de outras empresas juniores.

Sobre o terceiro objetivo da pesquisa (analisar o processo de tradução das práticas estratégicas, por meio do uso de ferramentas estratégicas pelos praticantes) no que diz respeito ao caso $\mathrm{B}$, as respostas dos entrevistados transpareceram que a tradução ocorre por meio da adaptação dos softwares utilizados (no caso, 0 Podio), e que esse processo tem participação de todos os membros, que discutem em reunião e em outros meios a forma de melhor utilizar o software. A entrevistada B2 informa o seguinte:

\begin{abstract}
O Podio foi a principal inovação, também há o Google Drive, que facilita um compartilhamento rápido de arquivos necessários, tem o Runrun.it para a gestão dos projetos (é um software mais focado em projetos), o Prezi para apresentações para clientes, o Wix para armazenamento de websites, alguns softwares da área financeira também. Muitos desses softwares são pagos, mas conseguimos acordos com as empresas para disponibilizar tais softwares gratuitamente.
\end{abstract}

Assim, para saber como ocorre a tradução de práticas estratégicas pelos praticantes no que diz respeito ao caso B, a tradução pode ser vista em certos aspectos como por transmissão ou por corrente. Os sistemas utilizados na empresa são obtidos diretamente das empresas que as desenvolvem, não passando por terceiros, sendo esse 0 aspecto da tradução por transmissão. 0 que passa por terceiros é a interpretação do uso desses softwares, que podem ser da própria empresa que as desenvolveram ou de outros usuários. Pelo tamanho pequeno da empresa, a inovação adotada não foi por completo, mas em parte, após uma análise de como essa ideia poderá ser adaptada à realidade da empresa.

\title{
4.3 Análise do caso C
}

O terceiro caso também é de uma empresa júnior, sediada no campus de São Cristóvão da UFS, vinculada ao Departamento de Computação. Fundada em 1997, a empresa é composta por estudantes dos três cursos de graduação em computação oferecidos na universidade - Engenharia de Computação, Ciência da Computação e Sistemas de Informação. Em seu website, a empresa afirma que busca "apresentar criatividade e inovação em seus trabalhos, proporcionando serviços de alto valor agregado". Os serviços oferecidos pela empresa são o desenvolvimento de websites e sistemas web, além de cursos e treinamentos, e a empresa informa que trabalha "com tecnologias consolidadas e promissoras para proporcionar aos nossos clientes e parceiros soluções inovadoras e de alta qualidade".

A empresa apresenta como missão "ser um agente de fomento empresarial, viabilizando o crescimento profissional e pessoal de seus membros através da interação entre os ambientes acadêmico e profissional, proporcionando aos nossos clientes e parceiros soluções inovadoras e de alta qualidade". Sua visão é "tornar-se referência de modelo de gestão entre as empresas juniores e ser reconhecida nacionalmente pela excelência de seus produtos e serviços, impactando positivamente no ecossistema de Tl". Os valores apresentados são "profissionalismo; criar, solucionar, inovar; determinação; sinergia; transparência; empreendedorismo; responsabilidade social".

Atualmente, existem 25 membros na empresa; a maioria foi admitida há pouco tempo, após um processo seletivo, o segundo no ano de 2015 - a alta rotatividade de pessoal é uma característica das empresas juniores, e não é diferente com esta empresa. Durante a pesquisa, os entrevistados informaram que o estado atual da empresa foi conquistado há pouco tempo - a empresa passou 5 anos sem atuação efetiva, o que levou à

Revista Alcance - Eletrônica - vol. 26 - n. 1 - Jan./Abr. 2019 
acumulação de dívidas na prefeitura e na Receita Federal, então alguns alunos se uniram para reerguer a empresa.

O entrevistado C1 foi o principal agente para o ressurgir da empresa júnior. Há um ano na empresa, tem 23 anos de idade e atua como Diretor Presidente, possui formação de técnico em eletrônica e está no $6^{\circ}$ período de Engenharia da Computação. Possui experiência na área de suporte à informática, docência em escola infantil e atualmente é assessor parlamentar da Assembleia Legislativa. $O$ entrevistado C2, 21 anos, atua como Diretor de Comunicação e Marketing, $7^{\circ}$ período de Engenharia da Computação e possui experiência anterior no desenvolvimento de softwares para empresas. Está há 1 ano na empresa.

O entrevistado C3, 21 anos, é Diretor de Tecnologia e atua na empresa há 1 ano. É graduando em Engenharia da Computação ( $3^{\circ}$ período), possui experiência anterior em suporte e também atua como técnico de suporte (terceirizado) do Tribunal de Justiça de Sergipe. 0 entrevistado C4, 23 anos, está há 7 meses na empresa, é graduando em Ciência da Computação ( $3^{\circ}$ período) e atua como Gerente de Projeto de Desenvolvimento de Softwares, e já trabalha na área de desenvolvimento há 5 anos e atualmente é analista de sistemas de um site de notícias. Por fim, o entrevistado C5 tem 18 anos e atua como desenvolvedor front-end. É graduando em Ciência da Computação ( $1^{\circ}$ período). Possui experiência profissional anterior em trabalhos free-lance e está na empresa há 4 meses.

Em relação ao objetivo de identificar as práticas estratégicas adotadas pelos praticantes, na empresa do caso $\mathrm{C}$, da mesma forma que no caso $\mathrm{B}$, há um foco no desenvolvimento individual, para que os valores adotados pela empresa se reflitam nos profissionais que vão para o mercado de trabalho, familiarizados com as principais metodologias e sistemas utilizados nas maiores empresas. 0 planejamento estratégico, segundo o entrevistado C1, é feito da seguinte forma:

O planejamento é norteado pelo material da Fundação Nacional da Qualidade, adaptado para a nossa realidade. A empresa tira uma semana inteira para elaborar o planejamento estratégico, área por área, revisando as metas anteriores e novas ideias a serem implementadas, o que é discutido e posteriormente registrado.

Para a empresa do caso $C$, as práticas estratégicas são desenvolvidas a partir de projetos, considerando a experiência dos empregados: eles começam com projetos menores (desenvolvimento de websites), para que em seguida possam efetuar projetos maiores, envolvendo diferentes áreas e tecnologias. A tradução de práticas estratégicas adotadas em empresas como Google e Facebook (citadas na entrevista) está relacionada a uma forma de trabalhar que favoreça a transparência das atividades entre todos os membros.

Quanto ao objetivo de identificar os processos de isomorfismo institucional, evidenciou-se que o isomorfismo normativo, em relação à seleção de pessoal, gera legitimidade a partir do tipo de formação técnica existente, voltada a uma dada tecnologia, escolhida de acordo com a necessidade do mercado. $\mathrm{O}$ isomorfismo mimético é percebido pela atuação por projetos da empresa, adequado ao ritmo de mudanças em que as empresas de TI são expostas, levando a uma atuação flexível e com alteração de prioridades. Por fim, o isomorfismo coercitivo ocorre com uma participação formal em associações de empresas juniores e uma atuação informal no ramo de TI, visto essa atividade não ser legalmente regulamentada, e a coerção é mais baseada em expectativas de mercado do que em mecanismos regulatórios. Sobre isso, o entrevistado C2 diz:

O planejamento é norteado pelo material da Fundação Nacional da Qualidade, adaptado para a nossa realidade. A empresa tira uma semana inteira para elaborar o planejamento estratégico, área por área, revisando as metas anteriores e novas ideias a serem implementadas, o que é discutido e posteriormente registrado.

Em relação ao objetivo de analisar o processo de tradução das práticas estratégicas, como a empresa do caso $\mathrm{C}$ se trata de uma empresa do ramo de computação, as adequações feitas são no sentido de adaptar cada sistema à necessidade de cada projeto. Podem ser usadas diferentes metodologias no processo de desenvolvimento e uso de um software, como o Scrum, Kanban e outros, e a possibilidade de se escolherem diferentes metodologias é uma forma de tradução dessas práticas, que facilitem a organização das informações e 
reduzam a centralização em algumas pessoas, de forma a tornar as informações visíveis a todos. 0 entrevistado C4 citou as fontes para o processo de tradução das práticas estratégicas:

As influências foram as empresas que já validaram essas novas tecnologias, que favorecem a transparência das atividades, permitem saber o que o outro está fazendo e me oferecer para auxiliar, a saber como está o andamento, se necessário.

Para saber como ocorre a tradução de práticas estratégicas pelos praticantes, a tradução para a empresa C pode ser entendida como por transmissão ou por corrente, com o uso de softwares e tecnologias obtidas diretamente com os fabricantes e considerando a opinião de especialistas do meio profissional, para saber quais são as tecnologias validadas pelo mercado. A utilização dessas tecnologias ocorre com base na interpretação de outras pessoas, não apenas de forma direta com a desenvolvedora do produto.

\section{CONSIDERAÇÕES FINAIS}

Nesta seção são apresentadas as interpretações das evidências empíricas à luz da base teórica adotada, além de recomendações e propostas para novos trabalhos a respeito dessa temática. Em relação à compreensão de como ocorre a tradução de práticas estratégicas pelos praticantes nas empresas $\mathrm{A}, \mathrm{B}$ e C, objetivo geral do estudo, isso deve ser considerado, conforme aponta Zilber (2006), um reflexo do fato de que muitos atores sociais não possuem contato direto com a prática adotada, e sim com as racionalizações dessa prática, construídas por atores em determinadas situações, sendo assim necessário traduzir o conteúdo dessa racionalização para ajustálo às necessidades da empresa.

Das três formas de tradução descritas por Sahlin e Wedlin (2008), que podem ser por transmissão, por corrente e mediado por outros atores e organizações, o fato de as empresas pesquisadas terem apresentado os três tipos, em diferentes graus, mostra que a forma de tradução adotada pela empresa (o que não ocorre de uma maneira plenamente consciente) depende de fatores diversos, como o tipo de empresa e ramo de atuação, os atores que efetuam essa tradução, a situação da empresa e o seu posicionamento no mercado, dentre outros. Evidencia-se a importância de os estrategistas atentarem para o campo organizacional, considerado um espaço com boas ideias (desde estratégias organizacionais até sistemas já legitimados pelo mercado) que podem ser imitadas pela organização.

A contribuição da Estratégia como Prática Social está no entendimento do papel da agência humana na construção e na execução da estratégia, pelas ações e pelas interações dos estrategistas. 0 papel de pessoas específicas (como o sócio fundador da empresa $\mathrm{A}$ ou o gerente técnico da empresa $\mathrm{C}$ ) em trazer novas ideias para a empresa, e a atuação de cada membro na tradução destas ideias, segundo Whittington (2006), mostram a estratégia como algo feito por pessoas por meio de fatores externos e internos à organização.

Já a Teoria Institucional contribui com o entendimento do que é o isomorfismo institucional e da sua atuação no processo de tradução, a partir da construção compartilhada de ideias, reformuladas em diferentes empresas e contextos, com suas próprias pressões e regras, e tal moldagem deve conter elementos familiares que os façam ser aceitas por quem as recebe. Durante a edição pode haver alguma mudança do significado ou do foco do que é transmitido; doutra forma, outras ideias permanecem as mesmas enquanto circulam pelo campo organizacional.

A convergência teórica entre tais perspectivas é necessária pois, isoladamente, ambas não explicam de forma abrangente e aprofundada a ligação entre o micro e o macroambiente. Segundo Dimaggio e Powell (2005), o desenvolvimento de uma visão balanceada entre atores e instituições parte de uma abordagem que traga uma explicação para o relacionamento entre a ação humana e as estruturas cujos atores estão imersos. Assim, com base nas perspectivas da Estratégia como Prática Social e da Teoria Institucional, pode-se ter a noção de que a estratégia não se forma com base em modelos de gestão ou tecnologias específicas, sem passar pelos atores de cada organização, a partir dos processos de interpretação do modelo, análise do contexto extraorganizacional e negociação entre diferentes atores.

É certo que essa convergência carece de consolidação. Boa parte das pesquisas institucionalistas se preocupa em compreender como os atores sociais são influenciados pelas instituições ou como determinados atores buscam construir instituições que atendam aos seus interesses. Sendo assim, é necessária uma 
investigação mais aprofundada acerca da influência da ação humana sobre a constituição e a reprodução das instituições. As diferentes formas de tradução encontradas nos casos pesquisados mostram que o campo de consultorias organizacionais pode ser mais bem explorado a partir de uma melhor secção do setor pesquisado ou do uso de outras metodologias de pesquisa de cunho mais quantitativo.

\section{REFERÊNCIAS}

Balogun, J., Huff, A. S., \& Johnson, P. (2003). Three responses to the methodological challenges of studying strategizing. Journal of Management Studies, 40(1), 197-224.

Berg, B. L. (2001). Qualitative Research Methods for the Social Sciences (4a ed). Needham Heights: Allyn \& Bacon.

Boxenbaum, E., \& Pedersen, J. S. (2009). Scandinavian institutionalism - a case of institutional work. In: Lawrence, T. B., Suddaby, R., \& Leca, B. (Eds.). Institutional Work: Actors and Agency in Institutional Studies of Organizations. Cambridge: Cambridge University Press.

Carter, C., Clegg, S. R., \& Kornberger, M. (2008). Strategy as practice? Strategic Organization, 6(1), 83-99.

Clegg, S., Carter, C., \& Kornberger, M. (2004). A "máquina estratégica": fundamentos epistemológicos e desenvolvimentos em curso. Revista de Administração de Empresas, 44(4), 21-31.

Collis, J., \& Hussey, R. (2005). Pesquisa em Administração (2a ed). Porto Alegre: Bookman.

Coraiola, D. M., \& Machado-da-Silva, C. L. (2008). Discurso organizacional e isomorfismo institucional: as mudanças gráficas em jornais brasileiros. Revista Eletrônica de Ciência Administrativa, 7(2), 1-13.

DiMaggio, P. J., \& Powell, W. W. (2005). A gaiola de ferro revisitada: isomorfismo institucional e racionalidade coletiva nos campos organizacionais. Revista de Administração de Empresas, 45(2), 74-89.

Golsorkhi, D., Rouleau, L., Seidl, D., \& Vaara, E. (2010). Introduction: what is strategy as practice? In: Golsorkhi, D., Rouleau, L., Seidl, D., \& Vaara, E. (Eds.). Cambridge Handbook of Strategy as Practice. Cambridge: Cambridge University Press.

Jarzabkowski, P. (2004). Strategy as practice: recursiveness, adaptation, and practices-in-use. Organization Studies, 25(4), 529-560.

Jarzabkowski, P., Balogun, J., \& Seidl, D. (2007). Strategizing: the challenges of a practice perspective. Human Relations, 60(1), 5-27.

Jarzabkowski, P., \& Spee, A. P. (2009). Strategy-as-practice: a review and future directions for the field. International Journal of Management Reviews, 11(1), 69-95.

Jarzabkowski, P., \& Whittington, R. (2008). A Strategy-as-practice approach to strategy research and education. Journal of Management Inquiry, 17(4), 282-286.

Johnson, G., Melin, L., \& Whittington, R. (2003). Guest editors' introduction: micro strategy and strategizing: towards an activity-based view. Journal of Management Studies, 40, 3-22.

Machado-da-Silva, C. L., \& Gonçalves, S. A. (2012). Nota técnica: a teoria institucional. In: Clegg, S., Hardy, C., \& Nord, W. (Org.) Handbook de Estudos Organizacionais: Modelos de análise e novas questões em estudos organizacionais. (Vol. 1, 1a ed, 6a reimpr.) São Paulo: Atlas.

Powell, W. W., \& Colyvas, J. A. (2008). Microfoundations of institutional theory. In: Greenwood, R.; Oliver, C.; Sahlin, K.; Suddaby, R. (Eds.) The SAGE Handbook of Organizational Institutionalism. Londres: SAGE Publications.

Rese, N., Kuabara, F. H. S., Villar, E. G., \& Ferreira, J. M. (2017). O vir a ser da estratégia como uma prática social. Revista de Administração Contemporânea, 21(2), 227-248.

Sahlin, K., \& Wedlin, L. (2008). Circulating ideas: imitation, translation and editing. In: Greenwood, R., Oliver, C., Sahlin, K., \& Suddaby, R. (Eds.) The SAGE Handbook of Organizational Institutionalism. Londres: SAGE Publications. 
Saunders, M., Lewis, P., \& Thornhill, A. (2007). Research Methods for Business Students (4a ed). Harlow: Pearson Education.

Suddaby, R., Seidl, D., \& Lê, J. K. (2013). Strategy-as-practice meets neo-institutional theory. Strategic Organization, 11(3), 329-344.

Tolbert, P. S., \& Zucker, L. G. (2012). A institucionalização da teoria institucional. In: Clegg, S., Hardy, C., \& Nord, W. (Org.) Handbook de Estudos Organizacionais: Modelos de análise e novas questões em estudos organizacionais (Vol. 1, 1a ed, 6a reimpr.). São Paulo: Atlas.

Whittington, R. (1996). Strategy as practice. Long Range Planning, 29(5), 731-735.

Whittington, R. (2006). Completing the practice turn in strategy research. Organization Studies, 27(5), 613-634.

Yin, R. K. (2001). Estudo de Caso: Planejamento e Métodos. Porto Alegre: Bookman.

Zilber, T. B. (2006). The work of the symbolic in institutional processes: translations of rational myths in Israeli high tech. Academy of Management Journal, 49(2), 281-303. 